\title{
A PALEOCLIMATIC MODEL OF THE MID-PLEISTOCENE CLIMATE TRANSITION
}

by

\author{
G. Deblonde and W.R. Peltier
}

(Department of Physics, University of Toronto, Toronto, Ontario, Canada M5S 1A7)

\section{ABSTRACT}

A one-dimensional time-dependent ice-sheet model is employed to simulate ice-volume variations throughout the Pleistocene epoch of Earth history. The model is based upon the explicitly-described physics of ice-sheet accumulation and flow and the physics of the viscoeleastic relaxation of the Earth under the weight of the ice load. The model of the viscoelastic relaxation of the Earth incorporates the vertical variation of density and viscosity of its interior in great detail. An abrupt variation of some of the parameters that govern the height of the ice-sheet equilibrium line, and a gradual increase in the strength of a generalized feedback mechanism that is turned on after mid-Pleistocene time, lead to simulation of ice volume that has the general features of observed $\delta^{18} \mathrm{O}$ records, in particular the new high-resolution oxygen-isotope record from site ODP 677 (Peltier and others, 1989).

\section{INTRODUCTION}

Spectral analysis of $\delta^{18} \mathrm{O}$ records and the application of other statistical techniques have shown that significant climatic transitions have occurred during the Pleistocene epoch (e.g. Pestiaux and Berger, 1984; Ruddiman and others, 1986; Maasch, 1988; Ruddiman and Raymo, 1988). Maasch (1988) concluded from the statistical analysis of several oxygen-isotope records and also sea-surface temperature time series distributed worldwide that there was an abrupt global transition in the $\delta^{18} \mathrm{O}$ records around $-900 \mathrm{ka}$. Prior to this mid-Pleistocene transition, the ice sheets were of moderate size. After that time their amplitudes increased, leading to lowered sea-surface temperatures and a global climate cooling. He showed that there was an abrupt transition in the mean; however, no firm conclusions could be made about the rapidity of the transition in the variance. A speculation as to why this might be is the existence of a gradual increase of the amplitude of the $100 \mathrm{ka}$ period after the mid-Pleistocene transition, that reaches a plateau around $450 \mathrm{ka}$ before present.

In this paper we present the results of ice-volume simulations for the entire Pleistocene that were obtained using a one-dimensional time-dependent ice-sheet model. The orbitally-forced one-dimensional ice-sheet model is briefly described in Section 2. The incorporation of a generalized feedback mechanism (Pollard, 1983a, b) leads to complete deglaciations throughout the entire late Pleistocene which are in fact independent of the time of initiation of the integrations; that is to say that if the integration was started for example at -2000 or $-900 \mathrm{ka}$, one would obtain complete deglaciations over the entire time spans considered. This is in disagreement with observations. A late-Pleistocene simulation of this type is described in Section 3. Multiple-window harmonic analysis (Thomson, 1982) and techniques for detection of a jump in the mean and and variance have been applied to the ODP 677 record (Peltier and Shackleton, 1989) from the Panama Basin which is of especially high resolution. This statistical information is employed to redesign the ice model so as to achieve an improved simulation using procedures described in section 4

\section{ICE-AGE MODEL FORMULATION}

The ice-age model includes the effects of the cryosphere, the asthenosphere, and the atmosphere. A detailed description of it has been provided in Deblonde and Peltier (1989). For present purposes it will suffice to begin with a very brief summary of its main characteristics.

The non-Newtonian flow of the ice sheet is assumed to be governed by a power law rheology. The evolution equation for the ice thickness $(H)$, which follows from conservation of mass, is highly non-linear and is solved in spherical coordinates for an axisymmetric spherical geometry. This evolution equation for $H$ is simply:

$$
\frac{\partial H}{\partial t}(\theta, \mathrm{t})=\frac{\lambda}{r \sin \theta} \frac{\partial}{\partial \theta}\left[\sin \theta H^{5}\left\{\frac{\partial h}{\partial \theta r}\right\}^{3}\right]+A
$$

in which $\theta$ is the co-latitude, $r$ is the radius of the Earth, $A$ is the net mass-balance function, $\lambda=$ $1.825 \times 10^{-11} \mathrm{~m}^{-3} \mathrm{~s}^{-1}$, and $h$ is the ice height above a given reference level (e.g. Birchfield and others, 1981).

The simulation of the bedrock depression $h^{\prime} \quad\left(h^{\prime}=\right.$ $H-h)$ takes into account the vertical variations of density and viscosity of the Earth's interior. The isostatic adjustment theory developed by Peltier (e.g. 1982) shows that $h^{\prime}$ is given by the following convolution integral:

$h^{\prime}(\theta, \phi, t)$

$$
=\iiint u_{\mathrm{r}}\left(\theta-\theta^{\prime}, \phi-\phi^{\prime}, t-t^{\prime}\right) \rho_{\mathrm{i}} H\left(\theta^{\prime}, \phi^{\prime}, t^{\prime}\right) \mathrm{d} \Omega^{\prime} \mathrm{d} t^{\prime}
$$

in which $\phi$ is the longitude and $u_{\mathrm{r}}$ is the Green function for radial displacement. Since this model is axisymmetric, Equation (2) with the addition of initial topography assumed to be in isostatic balance reduces to:

$$
\begin{aligned}
& h^{\prime}(\theta, t)=h_{0}^{\prime}(\theta)+ \\
& +\frac{3 \rho_{\mathrm{i}}}{\rho_{\mathrm{a}}} \sum_{\ell} P_{\ell}(\cos \theta) \iint H\left(\theta^{\prime}, t^{\prime}\right) \sin \theta^{\prime} P_{\ell}\left(\cos \theta^{\prime}\right) q_{\ell}\left(t-t^{\prime}\right) \mathrm{d} \theta^{\prime} \mathrm{d} t^{\prime}
\end{aligned}
$$

with the Love numbers $q_{\ell}$ given as follows:

$$
q_{\ell}(t)=\sum_{j=1}^{5} r_{j}^{l} \mathrm{e}^{-s_{j}^{l} t}+q_{l}^{\mathrm{E}} \delta(t) .
$$

$\rho_{\mathrm{a}}$ is the average density of the Earth $\left(5515 \mathrm{~kg} / \mathrm{m}^{3}\right), \rho_{\mathrm{i}}$ is the ice density, and $q_{l}^{\mathrm{E}}$ is the instantaneous elastic contribution to the response. $r_{j}^{l}$ is the amplitude of the mode of relaxation $j$ at degree $\ell$ and the $s_{j}^{\ell}$ are the inverse relaxation time constants. The relaxation strength is measured by the ratio of $r_{j}^{\ell}$ over $s_{j}^{\ell}$. The five strongest modes of relaxation are kept in the system (Peltier, 1982). A lithospheric thickness of $120 \mathrm{~km}$ and a lower mantle viscosity of $2 \times 10^{21} \mathrm{Pas}$ are also assumed. The net mass-balance function is prescribed (Oerlemans, 1980) as follows: 


$$
\begin{array}{ll}
A=a(h-E)-b(h-E)^{2} & \text { if }(h-E) \leqslant 1500 \mathrm{~m}, \\
A=0.56 \mathrm{~m} / \text { year } & \text { if }(h-E)>1500 \mathrm{~m}
\end{array}
$$

where $a=0.81 \times 10^{-3} \mathrm{~s}^{-1}$ and $b=0.3 \times 10^{-6} \mathrm{~m}^{-1} \mathrm{~s}^{-1} . E$ is the equilibrium line as is defined as follows:

$$
E(\cos \theta)=E_{0}-S\left(\cos \xi-\cos \theta_{0}\right)+k \delta Q_{S} ;
$$

$S$ is the slope of the equilibrium line and $\theta_{0}$ is a fixed co-latitude. For the simulations to be described based upon this model, we shall assume $S=0.1 \times 10^{-2}$ and $\theta_{0}=20^{\circ}$. $E_{0}$ and $k$ are given constants. $\delta Q_{\mathrm{S}}$ is the caloric summer insolation anomaly defined according to Milankovitch and has been computed after Berger (1978a, b).

\section{LATE-PLEISTOCENE ICE-VOLUME SIMULATIONS $(-700$ TO $0 \mathrm{ka})$}

The major ice retreats that are obtained with both a locally-damped and a thin-channel asthenospheric bedrock depression model are no longer so prominent when the bedrock despression is modelled by the viscoelastic model described above (Deblonde and Peltier, 1989). These differences are due to (1) a different dependence of the relaxation time on wavelength and (2) the variation of the relaxation strength with wavelength in the viscoelastic model. However, the addition of a generalized melt-water parameterization mechanism which depends on the time rate of change of the ice volume itself (Pollard, 1983a, b) leads to complete deglaciations but not to a maximum in harmonic amplitude at the 100 kyear period as was the case for the thin asthenospheric channel model (Pollard, 1982, 1982a, b). A time series of the ice volume for two different strengths of the feedback mechanism are shown in Figure 1. The linear correlation coefficient of the synthetic ice-volume record with SPECMAP (Imbrie and others, 1984) is 0.57 (Fig. 1; solid line).

\section{PLEISTOCENE ICE-VOLUME SIMULATIONS (-1900 TO $0 \mathrm{ka})$}

The same statistical techniques for the detection of the jump in the mean and variance as employed in Maasch (1988) have been applied to the planktonic $\delta^{18} \mathrm{O}$ record ODP 677 . The $\delta^{18} \mathrm{O}$ series in shown in Figure 2a. For this series, it is quite obvious from visual inspection that it has distinct properties before and after about $-900 \mathrm{ka}$. Figure $2 \mathrm{~b}$ is a time series of the running mean with a segment length of $300 \mathrm{ka}$. Figure $2 \mathrm{c}$ is a curve of the changing standard deviation with the same segment length. The signal-to-noise ratio for the detection of a jump in the mean is shown in Figure 2d. Two distinct peaks (that must be greater than 1.0 to be significant at the $99 \%$ level) are observed around

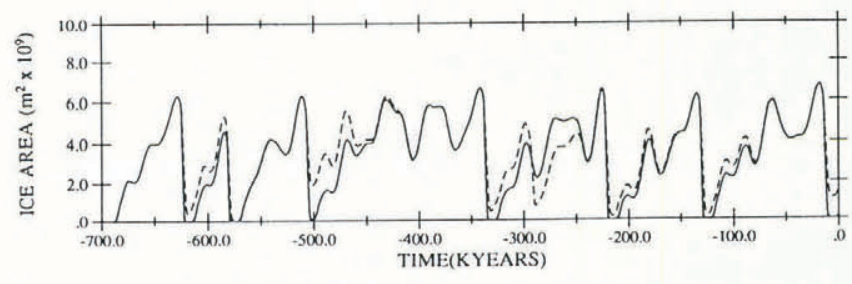

Fig. 1. Total ice cross-sectional area for the ice model with orbital forcing at $55^{\circ} \mathrm{N}$. The increases in height of the equilibrium line used in the GMP mechanism are at $1000 \mathrm{~m}$ (solid line) and $500 \mathrm{~m}$ (dahsed line). The function describing the increase in the height of the equilibrium line $\left(E^{+}\right)$is as follows: it is zero until a critical melt-water rate of $M_{1}$ is reached, the $E^{+}$increases linearly until the melt-water rate $(M)$ reaches a value of $M_{2}$ (such that $M_{2}>M_{1}$ ) where $E^{+}$is set equal to a chosen value $E_{2}^{+}$. for higher values of the melt-water rate, $E^{+}$is kept fixed at the value of $E_{2}^{+}$. For all cases considered in this paper, $M_{1}=12 \mathrm{~cm} \mathrm{year}^{-1}$ and $M_{2}=20 \mathrm{~cm} \mathrm{year}^{-1}$ unless specified otherwise. $E_{2}^{+}$varies between 500 and $1000 \mathrm{~m}$.

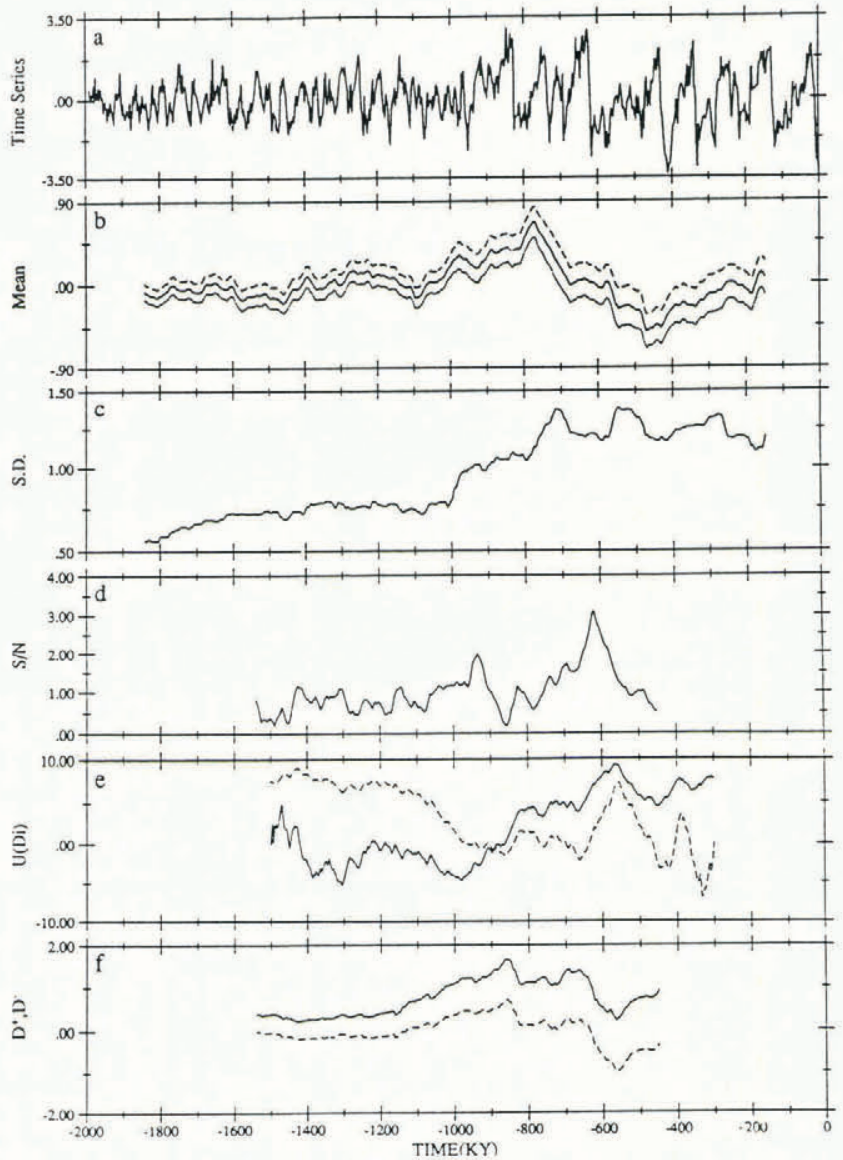

Fig. 2. Statistical analysis of site ODP $677 \delta^{18} \mathrm{O}$ record. (a) Normalized time series. (b) Running mean of the time series shown in (a) with segment length of $300 \mathrm{ka}$. (c) Changing standard deviation of the time series shown in (a) computed for a segment length of $300 \mathrm{ka}$. (d) Signal-over-noise ratio averaged over a range of segment lengths of $300-450 \mathrm{ka}$. (The confidence level is $99 \%$.) (e) Mann-Kendall rank statistic, $U(D i)$, for forward (solid) and retrograde (dashed) time series. (f) Test for jump in variance, $D^{+}$(solid line) and $D^{-}$(dashed line), averaged over the same segment lengths as in (d).

-950 and $600 \mathrm{ka}$. The signal-to-noise ratio has been computed for segment lengths in the range $300-450 k$ and then averaged. Figure $2 \mathrm{e}$ illustrates the Mann-Kendall rank statistic (Sneyers, 1975) for the forward and retrograde time series. An intersection of the curves occurs within the $95 \%$ confidence level around $-900 \mathrm{ka}$. Thus, the ODP 677 time series has a jump in the mean around $-900 \mathrm{ka}$ that is statistically significant. Figure $2 \mathrm{f}$ illustrates values computed from the $99 \%$ confidence intervals of the variance. If $D^{+}>0$ and $D^{-}>0$, then there is an increase in variance. These values have also been averaged for a range of $300-450 k$ to ensure that the results are independent of segment length. This last test does not point to a sharp transition in variance but rather hints toward a gradual increase of the variance and hence a possible gradua increase of the amplitude of the $100 \mathrm{ka}$ cycle. The ratio of the standard deviation after and before $-900 \mathrm{ka}$ is 1.75 and this is statistically significant ( $F$-test applied to a ratio of variances).

This statistical input has been used to develop a simulation of ice volume over the entire range of Pleistocene time. The one-dimensional ice model is forced externally by the orbital variations. If one assumes that orbital reconstructions are correct in their prediction that the nature of the forcing has not changed significantly within the Pleistocene time then a mid-Pleistocene transition is clearly not obtainable with such a model. However, it is nevertheless possible to evaluate how well such a model would be able to reproduce this transition given further information as input to it. Additional degrees of freedom may be added to the system by varying the height of the 
TABLE I. DESCRIPTION OF MODELLED ICE-VOLUME CASES

$\begin{array}{ccccc}\text { Case } & E_{0} & k & \text { Transition time } & \begin{array}{c}\text { Lat. of orbital } \\ \text { forcing }\end{array} \\ & \mathrm{m} & \mathrm{m}\left(\mathrm{W} \mathrm{m}^{-2}\right)^{-1} & \text { kyear } & { }^{\circ} \mathrm{N} \\ 1 & 700,550 & 24,35 & -1000,-800 & 55,55 \\ 2 & 700,550 & 24,35 & -900,-900 & 55,55 \\ 3 & 725,550 & 24,35 & -1000,-800 & 55,55 \\ 4 & 700,550 & 24,35 & -1000,-800 & 65,55\end{array}$

Height of equilibrium line Transition times increase

m

$\begin{array}{lrc}1 & 0,800 & -800,-400 \\ 2 & 0,800 & -800,-400 \\ 3 & 1000,1000 & \text { All times } \\ 4 & 0,800 & -800,-400\end{array}$

Linear correlation coefficients of modelled cases with ODP 677 series

Case

Correlation time intervals (ka)

$-1990,0$
0.56
0.56
0.40
0.54
-

$-1990,-900$

$-900,0$

$-700,0$

1

1
2
3

0.48
0.46
0.36
0.43

0.58

0.59

0.42

0.58

0.62

0.62

0.58

0.62

0.81

equilibrium line at $\theta_{0}\left(E_{0}\right.$ in Equation (4)), the sensitivity to the orbital forcing ( $k$ in Equation (4)) and the strength of the generalized melt-water parameterization (GMP). $E_{0}$ is one of the variables that controls the maximum ice volume. Raising the equilibrium line generates a warmer climate and therefore smaller overall maxima in ice mass. $k$ controls the standard deviation of the ice volume. Using a lower value of $k$ results in a lower value for the standard deviation of the ice volume. The question as to how fast $E_{0}$ and $k$ might change can be assessed by comparing model output with the $\delta^{18} \mathrm{O}$ time series ODP 677.

The gradual transition of the $100 \mathrm{ka}$ amplitude is simulated by changing the strength of the sudden increase in equilbrium-line height that occurs when a critical value of ice volume time rate of change is obtained which sets off a wastage process. It is assumed that the GMP mechanism is absent before $-900 \mathrm{ka}$ and not as strong during a $400 \mathrm{ka}$ transition period. The linear correlation coefficients for the cases discussed in this paper are listed in Table I. As expected, using a constant GMP during the entire Pleistocene leads to several unobserved complete deglaciations (case 3). Starting the GMP mechanism at $-800 \mathrm{ka}$ and gradually increasing its strength to $-400 \mathrm{ka}$ and then keeping it constant gives rise to a series that has a relatively close fit with the ODP 677 series. Starting the GMP mechanism at $\rightarrow 900 \mathrm{ka}$ instead of $-800 \mathrm{ka}$ leads to very similar results. The linear correlation coefficient of the simulated time series with SPECMAP for the time span -700 to $0 \mathrm{ka}$ increased from 0.57 to 0.67 (case 1). The same coefficient for ODP 677 is 0.62 . One should note that the correlation coefficient between SPECMAP and ODP 677 over the last $700 \mathrm{ka}$ is 0.81 , which rules out the expectation of obtaining a correlation coefficient of 1 between the model and individual observed time series. The values of $k$ and $E_{0}$ giving rise to the highest correlation coefficients as well as to a similar ratio in standard deviation of the ice volume are 24 and $35 \mathrm{~m}\left(\mathrm{~W} \mathrm{~m}^{2}\right)^{-1}$, respectively and $700-550 \mathrm{~m}$, respectively, before and after a transition period that is centred around $-900 \mathrm{ka}$. The change in $E_{0}$ corresponds to a change of about $1{ }^{\circ} \mathrm{C}$ using the current value of the atmospheric lapse rate $\left(-6.5^{\circ} \mathrm{C} \mathrm{km}^{-1}\right)$. The change in $k$ of about $30 \%$ suggests the existence of a less

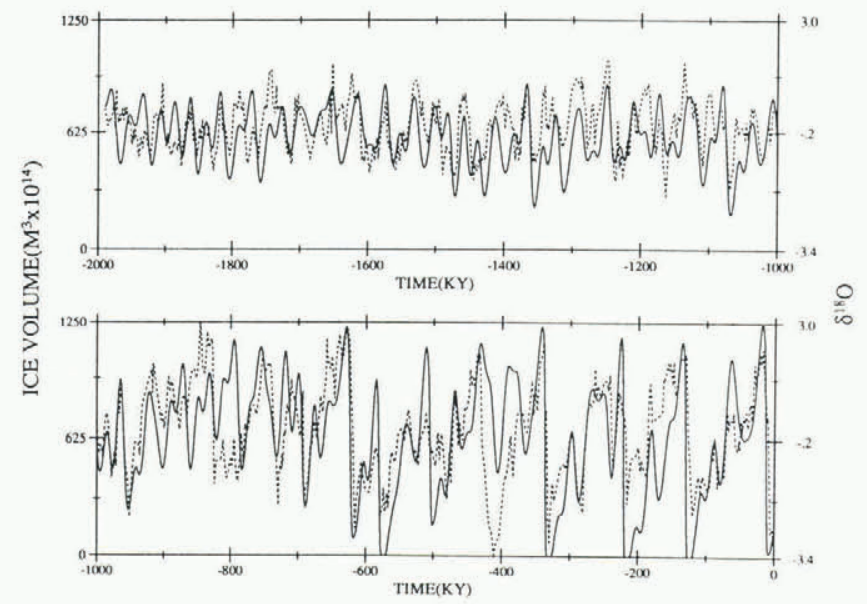

Fig. 3. Modelled ice-volume time series for case 1 (Table I) (solid line) and ODP $677 \quad 8^{18} \mathrm{O}$ time series (dashed line).

sensitive climate system before $-900 \mathrm{ka}$. As can be seen from the linear correlation coefficients (cases 1 and 2), it is not possible to deduce in a convincing manner that the transition in $E_{0}$ and $k$ was rapid (i.e. less than $200 \mathrm{ka}$ ). The ratio of the standard deviation of case 1 (Fig. 3) before and after $-900 \mathrm{ka}$ is 2.1. A harmonic analysis for the time span from -900 to $0 \mathrm{ka}$ for both case 1 and ODP 677 (Figs 4 and 5) shows that the modelled $100 \mathrm{ka}$ amplitude is inadequate. However, if the harmonic analysis is confined to
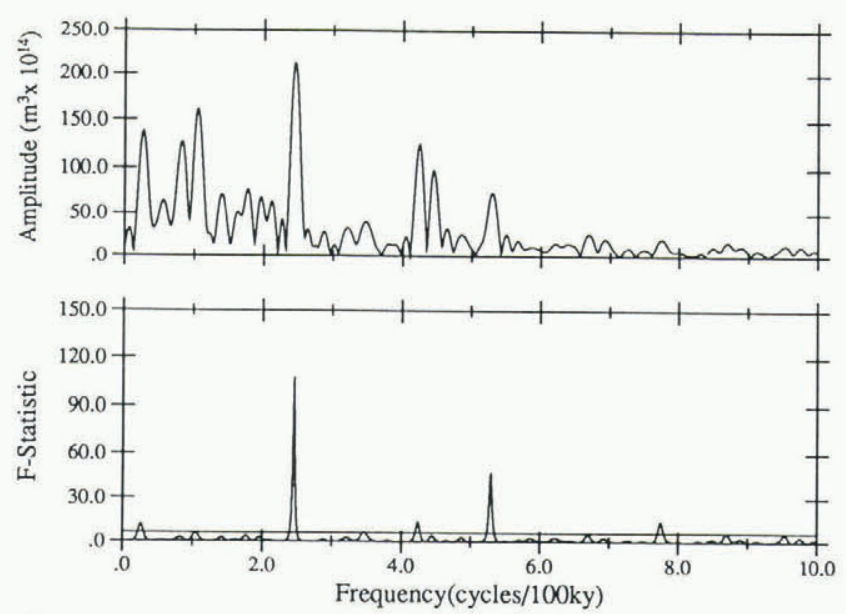

Fig. 4. Multiple window harmonic analysis of the ice volume for case 1 for the time series covering -900 to $0 \mathrm{ka}$. The top figure shows the harmonic amplitudes. The bottom figure shows the $F$-variance ratio of 2 and 8 degrees of freedom. Peaks above the horizontal lines are significant above the $97.5 \%$ point. Five windows have been used and $N W=8$ with $N=901$. A linear regression line has been subtracted from the time series.
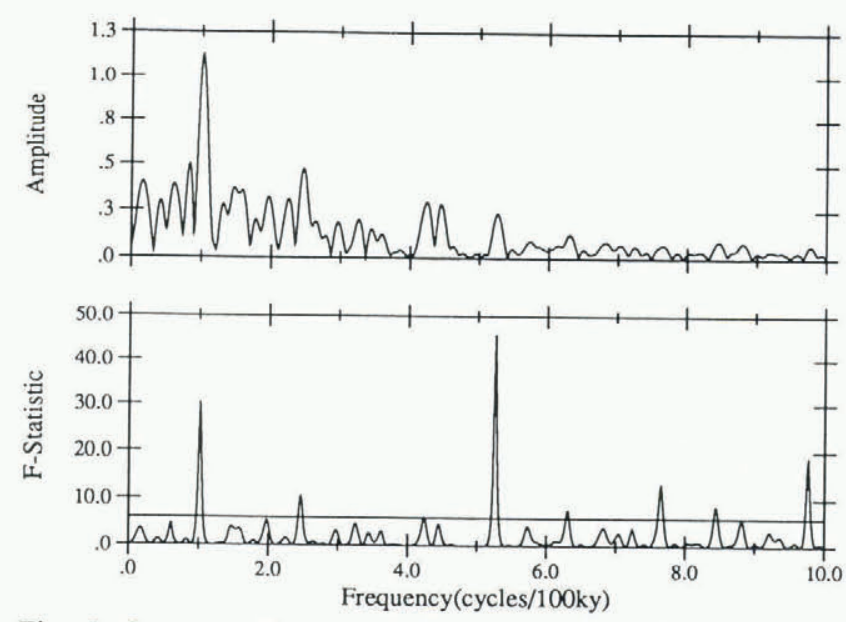

Fig. 5. Same as Figure 4 but for the ODP 677 time series covering -900 to $0 \mathrm{ka}$. 

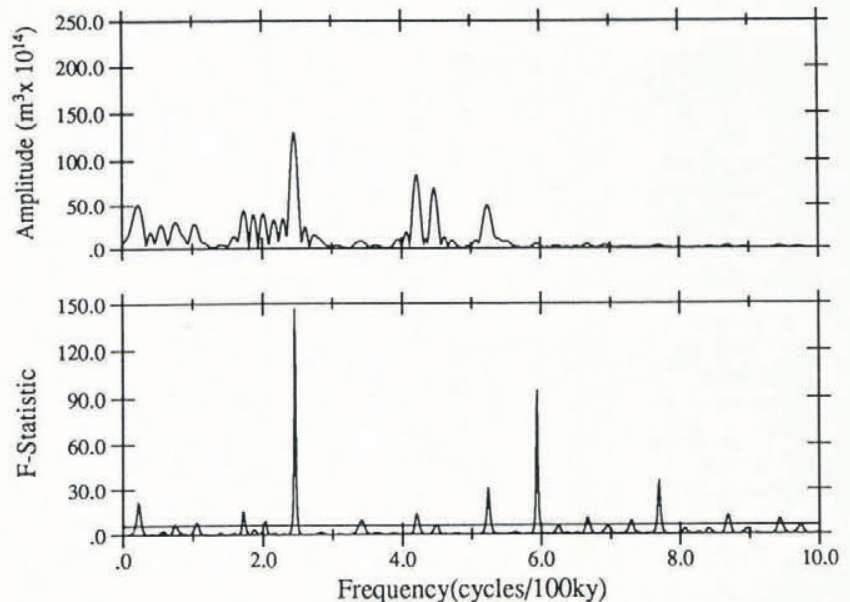

Fig. 6. Same as Figure 4 but for the modelled time series of ice-volume case 1 covering -1990 to -900 ka and $N=$ 1091.
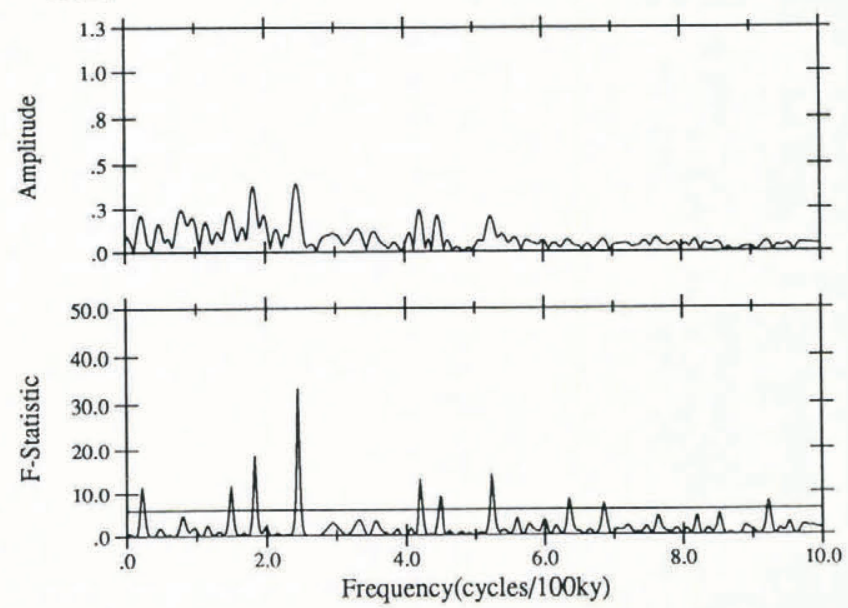

Fig. 7. Same as Figure 4 but for the ODP 677 time series covering -1990 to $-900 \mathrm{ka}$ and $N=1091$.

the last $400 \mathrm{ka}$, then the amplitude for both cases is a maximum at the $100 \mathrm{ka}$ period. The harmonic analysis of the modelled time series before $-900 \mathrm{ka}$ (case 1) shows similarities in relative amplitude at the 41,23 , and $19 \mathrm{ka}$ cycles provided the orbital forcing is taken at $55^{\circ} \mathrm{N}$ (Figs 6 and 7). The modelled maximum southern latitudinal extent of the ice sheets before $-900 \mathrm{ka}$ is $3^{\circ}$ latitude further north. Using an orbital forcing at $65^{\circ} \mathrm{N}$ before $-900 \mathrm{ka}$ (case 4) since the ice sheets did not extend as far south does increase the amplitude of the $41 \mathrm{ka}$ cycle and hence does not give rise to as good a fit with the observations.

\section{CONCLUSIONS}

By introducing further degrees of freedom in the one-dimensional ice-sheet model that includes a GMP feedback mechanism, it is possible to simulate the general features of the mid-Pleistocene climate transition and the gradual increase of the amplitude of the $100 \mathrm{ka}$ cycle after this climatic change. The reason for the rapidity of the mid-Pleistocene transition (probably $<200 \mathrm{ka}$ ) is still an open question.

According to the model, changes in $E_{0}$ and $k$ around $\rightarrow 00 \mathrm{ka}$ of $250 \mathrm{~m}$ and $11 \mathrm{~m}\left(\mathrm{~W} \mathrm{~m}^{-2}\right)^{-1}$, respectively, and the introduction of the GMP mechanism around $-900 \mathrm{ka}$ are necessary to simulate the observed deep sea-core record changes. The changes to $E_{0}$ and $k$ are necessary to simulate the reduction in ice-sheet volume before about $-900 \mathrm{ka}$, and the changes in the strength of the GMP mechanism are ncessary to simulate the appearance and increase in $100 \mathrm{ka}$ amplitude after the mid-Pleistocene transition. Possible physical mechanisms causing these changes include tectonic uplift (Ruddiman and Raymo, 1988) and variations in the oceanic thermohaline circulation (e.g. Sachs, 1976; Ruddiman and McIntyre, 1981; Manabe and Bryan, 1985; Boyle and Keigwin, 1987). Cyclic variations in carbon dioxide may be important for individual $100 \mathrm{ka}$ cycles (Shackleton and
Pisias, 1985; Barnola and others, 1987). It is also conceivable that the long-term variations ( $>100 \mathrm{ka})$ of carbon dioxide could also have changed over the Pleistocene epoch.

\section{REFERENCES}

Barnola, J.M., D. Raynaud, Y.S. Korotkevich, and C. Lorius. 1987. Vostok ice core provides 160,000-year record of atmospheric $\mathrm{CO}_{2}$. Nature, 329(6138), 408-414.

Berger, A. 1978a. Long-term variations of caloric insolation resulting from the Earth's orbital elements. Quat. Res., 9(2), 139-167.

Berger, A. 1978b. Long-term variations of daily insolation and Quaternary climatic changes. J. Atmos. Sci., 35, 2362-2367.

Birchfield, G.E., J. Weertman, and A.T. Lunde. 1981. A paleoclimate model of Northern Hemisphere ice sheets. Quat. Res., 15(2), 126-142.

Boyle, E.A. and L. Keigwin. 1987. North Atlantic thermohaline circulation during the past 20,000 years linked to high-latitude surface temperature. Nature, 330(6143), 35-40.

Deblonde, G. and W.R. Peltier. 1989. A one-dimensional model of the Pleistocene ice volume climate transition. Manuscript in preparation.

Imbrie, J., and 8 others. 1984. The orbital theory of Pleistocene climate: support from a revised chronology of the marine $\delta^{18} \mathrm{O}$ record. In Berger, A., J. Imbrie, J. Hays, G. Kukla, and B. Saltzman, eds. Milankovitch and climate. Dordrecht, etc., D. Reidel Publishing Company, 269-305.

Maasch, K.A. 1988. Statistical detection of the midPleistocene transition. Climate Dyn., 2, 133-143.

Manabe, S. and K. Bryan, jr. 1985. $\mathrm{CO}_{2}$-induced change in a coupled ocean-atmosphere model and its paleoclimate implications. J. Geophys. Res., 90(C6), 11,689-11,707.

Oerlemans, J. 1980. Model experiments on the 100,000-yr glacial cycle. Nature, 287(5781), 430-432.

Peltier, W.R. 1982. Dynamics of the ice age Earth. $A d v$. Geophys., 24.

Peltier, W.R. and N.J. Shackleton. 1989. An objective technique for the inference of time scale in a deep sea sedimentary core: application to ODP Site 677. Manuscript in preparation.

Pestiaux, P. and A. Berger. 1984. An optional approach to the spectral characteristics of deep sea climatic records. In Berger, A., J. Imbrie, J. Hays, G. Kukla, and B. Saltzman, eds. Milankovitch and climate. Dordrecht, etc., D. Reidel Publishing Company, 417-445.

Pollard, D. 1982. A simple ice sheet model yields realistic 100 kyr glacial cycles. Nature, 296(5855), 334-338.

Pollard, D. 1983a. A coupled climate-ice sheet model applied to the Quaternary ice ages. J. Geophys. Res., 88(C12), 7705-7718.

Pollard, D. 1983b. Ice-age simulations with a calving ice-sheet model. Quat. Res., 20(1), 30-48.

Ruddiman, W.F. and A. McIntyre. 1981. Oceanic mechanisms for amplification of the 23,000-year ice-volume cycles. Science, 212(4495), 617-627.

Ruddiman, W.F. and M.E. Raymo. 1988. Northern Hemisphere climate regimes during the past $3 \mathrm{Ma}$ : possible tectonic connections. Philos. Trans. R. Soc. London, Ser. $B, 318,411-430$.

Ruddiman, W.F., N.J. Shackleton, and A. McIntyre. 1986 In Summerhayes, C.P. and N.J. Shackleton, eds. North Atlantic palaeoceanography, 155-173. (Geological Society Special Publication 21.)

Sachs, H.M. 1976. Evidence for the role of the oceans in climatic change: tests of Weyl's theory of ice ages. $J$ Geophys. Res., 81(18), 3141-3150.

Shackleton, N.J. and N.G. Pisias. 1985. In Sundquist, E.T. and W.S. Broecker, eds. The carbon cycle and atmospheric $\mathrm{CO}_{2}$ : natural variations Archean to present. Washington, DC, American Geophysical Union, 303-317. (Geophysical Monograph 32.)

Sneyers, R. 1975. Sur l'analyse statistique des séries d'observations. Geneva, World Meteorological Organization. (Technical Note 143.)

Thomson, D.J. 1982. Spectrum estimation and harmonic analysis. Proc. IEEE, 70(9), 1055-1096. 